\title{
Spatial patterns and stability of topsoil water content in a rainfed fallow cereal field and Calcisol-type soil
}

\author{
López-Vicente $\mathrm{M}^{*}$, Quijano L, Navas A \\ Department of Soil and Water, Estación Experimental de Aula Dei, EEAD-CSIC. Avda. Montañana 1005, 50059 \\ Zaragoza, Spain \\ ${ }^{*}$ Corresponding author. E-mail: $\underline{\text { mvicente@eead.csic.es; }}$ mlopezvicente@gmail.com
}

Article history: Received: 26 February 2015; Received in revised form: 3 June 2015; Accepted: 18

July 2015; Final version published online (www.elsevier.com/locate/agwat): 7 August 2015,

http://dx.doi.org/10.1016/j.agwat.2015.07.009

Elsevier B.V.: Agricultural Water Management 161, 41-52; Issue November 2015.

\begin{abstract}
Topsoil water content (TSWC) is a key factor for crop establishment and subsequent production, runoff generation, soil detachment, and other soil processes. TSWC is one of the most variable soil properties due to the complexity of water fluxes in the unsaturated zone. The studies about TSWC in cultivated Calcisols are limited and almost inexistent under fallow treatment in rainfed cereal fields. We hypothesize that certain wetness characteristics (patterns, ranges and changes) of a soil portion remain over time. This study seeks to identify the spatial patterns of TSWC and their temporal stability in a Mediterranean fallow rainfed cereal field (1.6 ha, partial stubble retention, no weed growth allowed) and Haplic Calcisoltype soil. During 15 months (December 2009 to February 2011) and 25 field surveys measurements were made at 156 points ( 3 values per point) by using a frequency-domain probe. Values of TSWC varied significantly and four humidity periods were identified using antecedent rainfall and evapotranspiration values: wet (November - February, 27.1\% vol. on average), spring (March - June, 18.8\% vol.), dry (July - September, 12.1\% vol.) and wettingup (October, 18.8\% vol.). The relative differences within the field decreased under wet conditions and were higher in the dry surveys. The combined analysis of the standard deviation of the relative differences (SDRD) and the maps of TSWC showed that the spatial patterns of both the water content and the value changes were not stable at short-term. However, eight water content zones were defined at long-term supporting the initial
\end{abstract}


hypothesis: wettest $(23.8 \%$ vol.), driest $(16.8 \%$ vol. $)$, stable $(S D R D<0.134)$ and moist and dry, medium stability and moist and dry, most variable $(S D R D>0.247)$ and moist and dry. Satisfactory correlations were obtained with two topographic factors (average slope of the contributing area and convexity) and four soil properties (rock, silt, carbonates and the water content at field capacity) and correlations improved in the wet period related to the dry period. A different time response of the TSWC values appeared in the wet (between 2 and 3 days) and dry (6 and 7 days) periods related to the antecedent rainfall and evapotranspiration. The different water content zones presented different values of the soil and topographic factors that explain the different temporal stability of the relative differences in TSWC.

Keywords: Topsoil water content; Stability analysis; Rainfed cereal; Fallow; Calcisol.

\section{Introduction}

Soil water content (SWC) is one of the most limiting factors for crop production by both water deficit and excess (Qin et al., 2013; Saue and Kadaja, 2014) and is especially relevant in semi-arid and sub-humid areas where irregular soil water content dynamics are frequent (Viola et al., 2012). Additionally, SWC in the uppermost layer, the topsoil (TSWC), which governs seedling establishment is a more limiting factor for crop yield (e.g. sunflower; Aboudrare et al., 2006) than total SWC at planting. On the other hand, the antecedent TSWC is a significant factor to predict runoff generation and coefficients (Penna et al., 2015) and also soil detachment at the first stages of an erosive event (Yu et al., 2014).

Most climate models forecast an increase in temperature and a decrease in precipitation at the end of the $21^{\text {st }}$ century (Milly et al., 2005). Mediterranean areas are subject to dramatic changes in a global change scenario in which SWC will decline and saturation conditions will be increasingly rare and restricted to periods in winter and spring (García-Ruiz et al., 2011). Therefore, soil water resources should be studied in detail within the frame of sustainable agriculture and natural resources management.

In most soils the values of the physical properties vary considerably along the space (López-Vicente et al., 2008), high anisotropy ratio, and especially those related to hydrologic processes due to the complex water fluxes in the unsaturated zone (Espejo et al., 2014). The TSWC also varies throughout the seasons (López-Vicente et al., 2009) although there is a certain long-term temporal stability of this variability (Vachaud et al., 1985, Hu et al., 2013). At catchment scale Garcia-Estringana et al. (2013) found under Mediterranean conditions lower regimes of SWC on hillslopes under forest cover than in downslope areas covered with 
grasses, though these differences were not persistent through the year. And Navas et al. (2008) found in the Central Spanish Pyrenees a positive correlation between soil water content and other soil properties (field capacity, permanent wilting point) and with the ratio of the natural vegetation recovery too. At field scale Orfánus and Eitzinger (2010) analyzed how textural changes influence the variability of SWC in cultivated Gleysols and Regosols, and Munoz-Pardo et al. (1990) also found that the time stability of SWC may be explained by soil texture (silt + clay).

Different management practices (no-tillage with spontaneous vegetation cover and conventional tillage) affect the water content levels such as Palese et al. (2014) found in a rainfed olive orchard in S Italy. The different tillage systems not only may affect the water storage efficiency at annual scale but also during fallow, cereal root growth and yield (Lampurlanés et al., 2002). There is wide evidence that fallow practices (allowing weeds and volunteer crops, chemical weed control, mechanical weeding, grassing, straw mulching, rock fragment cover) can improve soil water accumulation and thus buffer the negative effects of dry seasons on crop yields (López et al., 1996; Oliver et al., 2010). Other studies conclude that accumulation of soil water in fallows is inefficient due to high evaporation and runoff losses (Qin et al., 2013). Fallowing is especially common in legume, forage and cereal crops (Soldevilla-Martinez et al., 2013) and even result necessary in the arid and semi-arid areas of West-Asia and North-Africa (Ryan et al., 2009) and in the low-precipitation zone ( $<300 \mathrm{~mm}$ per year) of the USA Pacific Northwest (Bewick et al., 2008). Fallowing is less common or inexistent in temperate landscapes.

In Mediterranean cultivated soils fallow is a traditional system, usually lasting 16 months, from July to October of the next year (Lampurlanés et al., 2002). However, there is few literature about temporal and spatial variability on TSWC in fallow cereal fields: Moret et al. (2007) measured and simulated soil water loss under three tillage management systems and fallows in the semiarid areas of NE Spain; and Pala et al. (2007) compared in Syria the longterm effects of seven wheat-based rotations on soil water dynamics and water use efficiency for crop yield. In SE Spain Cammeraat et al. (2010) investigated the redistribution of soil water in relation to natural vegetation development and land abandonment with artificial rain, and Oliver et al. (2010) simulated the potential benefits of long fallows in cereal crop rotations in W Australia. More recently, Ursino et al. (2014) studied in small closed plots (15 $\mathrm{m}^{2}$ ) in Italy the effects on several hydrological properties of fallow practices in soils after irrigation. 
Soil water content and dynamics are clearly different for each soil type. Many studies have been done in Vertisols (e.g. Baskan et al., 2013; Ackerson et al., 2014) and to less extent, in Leptosols (Baskan et al., 2013), in cultivated Sodosols (Lawrence et al., 1994), Gleysols and Regosols (Orfánus and Eitzinger, 2010) and in Alfisols (Pathak et al., 2013). Previous studies on SWC in Calcisols are scarce in spite of being a common soil in agricultural Mediterranean landscapes. Celano et al. (2011) assessed the spatial and temporal variability of SWC in olive orchards in Italy managed with and without cover crops. In Spain, Ramos et al. (2011) studied the effect of four soil management practices on the water content levels in rainfed almond orchards and Fernández-Ugalde et al. (2009) found in semiarid cultivated soils with barley an increase of water availability under no-tillage practice in comparison with conventional tillage. In Central France, Gabrielle et al. (2006) measured the soil water content in contrasting wheat-cropped soils. Besides these studies, we have only found one article in the literature about soil water content in a cultivated Calcisol under fallow treatment. In this article Lampurlanés et al. (2002) analyzed the effect of one year fallow treatment on the water storage and efficiency in a crop rotation barley/fallow although these authors did not study in detail the spatial and temporal dynamics of TSWC.

To our knowledge there is a gap in studies about the spatial structure of TSWC and its temporal stability in cultivated cereal Calcisols under fallow treatment. In this study we have selected a rainfed fallow cereal field under homogeneous soil type (Haplic Calcisol) conditions to characterize and analyse the spatial patterns and temporal stability of TSWC. Despite the well-known high variability of topsoil water content we hypothesize that it has a spatial structure with a characteristic temporal variability pattern. To achieve this goal we measured the TSWC on a 10x10m grid, every 15 days during 15 months (Dec'2009 Feb'2011) in a 1.6 ha-field of the Spanish Central Pre-Pyrenees by using a frequency-domain probe. The spatial patterns of water content and their temporal stability are firstly analyzed with statistical indicators. Then, values of TSWC are correlated with several topographic and soil physical properties and ratios and their temporal changes with two hydrologic (rainfall depth and evapotranspiration) and one climatic (solar radiation) parameters. The sound assessment of the TSWC patterns and their temporal stability (stable-dry, stable-wet, stablemedium) will be of interest for hydrological and agronomic research and can be used also to propose management practices to mitigate the negative consequences of rainfall scarcity in rainfed agricultural lands and other fragile though productive agro-ecosystems. 


\section{Materials and methods}

\subsection{The rainfed fallow cereal field on Calcisol-type soil}

A 1.6 ha fallow field was selected due to its physiographic characteristics. The field is classed as a nearly closed-hydrological unit due to the cutting-connectivity effect of the landscape linear elements (LLEs) that surround the study area (Quijano et al., 2013) (Figure 1a). It has homogeneous solar radiation conditions (SE facing) and a mean slope steepness of 9\%. The field is delimited by a paved trail and a stone wall to the north and by a small drainage ditch to the west, whereas to the east and south it borders on the La Reina ephemeral stream. Scattered short holm oaks surround the field but their shadow influence on the water content is negligible. During rainfall events with high intensity peaks and depths overland flow coming from near fields' upslope can enter into the field. The field is located in the lower part of the La Reina subcatchment within the Vandunchil stream catchment (Aragón river basin) in the northern part of the Ebro river basin (NE Spain) (Figure 1b). In a previous study eight hydrological units (HU) were identified: five in the northern part of the field with several outlets to the stream that present an undulating topography, and three HU with more gentle topography that cover the southern part of the field and converge in one outlet (LópezVicente et al., 2015). Soils are classified as Haplic Calcisols (Figure 2a) with low soil organic matter content (0.5-2.6\%), high carbonate contents (ca. $40 \%$ ) and texture is mainly silt loam and silty clay loam and in some cases sandy loam, loam and clay (Quijano et al., 2014).

The field has been cultivated for cereals during more than 150 years and consequently the soil is thoroughly mixed in the plough layer $(25-30 \mathrm{~cm})$. In situ field observations revealed that soil redistribution from tillage occurs although to a lesser extent than water erosion, which is triggered by the rills and ephemeral gully systems (López-Vicente et al., 2015). The cereal field was last harvested in June 2007 and from that date onwards the field has remained fallow (partial stubble retention, no weed growth allowed) for research purposes (Figure 1c). Before fallowing the field was managed with minimum tillage during 15 years. Vegetation clearance practices were implemented to prevent scrub growth and so the soil surface has remained almost bare and with very low soil roughness since that date.

The climate is continental Mediterranean with two humid periods, one in spring (April and May) and a second in autumn (from September until December) that summarizes $63 \%$ of the total annual precipitation. Summers are usually dry with occasional thunderstorms and winters are temperate and relatively dry (Figure $2 \mathrm{~d}$ ). There are eleven active weather stations (WS) surrounding the study area. Of these WS we use data from the Caseda (Spanish Meteorology Agency, AEMET) and Uncastillo (Ebro river basin Water Authorities, CHE) 
weather stations, located $15.9 \mathrm{~km}$ north west and 10.4 south east of the fallow field, respectively. A synthetic WS, at daily-temporal resolution, has been calculated with the rainfall values from these two WS for the period 1992-2012 (21 years): i) the average annual rainfall depth was $556 \mathrm{~mm}$ with strong inter-annual oscillation of 96\% (from $393 \mathrm{~mm}$ in 2001 till $768 \mathrm{~mm}$ in 1997); and ii) the highest rainfall depth is usually recorded in October (77 mm on average). Annual maximum reference evapotranspiration $\left(E T_{0}, \mathrm{~mm}\right)$ reaches $1156 \mathrm{~mm}$. Rainfall events of high intensity happen in June, July, September and October, with average values of maximum rainfall intensity in $30 \mathrm{~min}, I_{30}$, higher than $4 \mathrm{~mm} \mathrm{~h}^{-1}$ and above $6 \mathrm{~mm} \mathrm{~h}^{-1}$ in October (Figure 2d). Average $I_{30}$ keeps below $2 \mathrm{~mm} \mathrm{~h}^{-1}$ between November and February.

\subsection{Topsoil water content measurements}

A frequency-domain probe (Delta-T SM200) was used to measure the topsoil water content (TSWC). This device has a portable/handheld reading unit for field measurements and has a configuration of two rods that are inserted in the soil up to $51 \mathrm{~mm}$ depth (Figure $2 \mathrm{~b}$ ). The SM200 instrument uses a soil property called apparent dielectric constant of the soil to estimate volumetric water content at initial conditions ( $\theta_{0}, \%$ vol.) with an accuracy $\pm 0.03 \mathrm{~m}^{3}$ $\mathrm{m}^{-3}$. Although soil water content behavior changes at different soil depths, in this work we only characterized topsoil water content because processes of soil water storage and even runoff generation are mainly controlled by the mechanisms of initially soil surface water repellency, topsoil infiltration and changes in topsoil water content (Gomi et al., 2008), especially in Mediterranean soils where dry conditions are frequent. We assumed that water extraction from the vegetation roots surrounding the field do not affect the water content in the upper portion of the soil near the boundary of the field.

The TSWC was measured in 25 field campaigns every 15 days comprising the period December 2009 - February 2011 (Figure 2c). A total of 156 measurement points (98 points / ha) were established following a regular net with a distance of $10 \mathrm{~m}$ between points that entirely cover the field. Measurement points were identified in the field by using angle top-T signs hammered in the soils that guarantee the accurate location of measurements during each campaign. Three measurements of $\theta_{0}$ were done in each point and the average value was estimated as the representative value. A total of 11,700 TSWC measurements were done. Moreover, each survey was performed in one day to avoid any temporal change of the soil water content conditions. There was not recorded any rainfall event during each campaign and thus measured values suffered low variation. 


\subsection{Spatial patterns and temporal stability of the TSWC}

There is a wide range of techniques and methods to analyze soil water content fields that include temporal classical statistical and geostatistical tools, stability analysis, wavelet analysis, empirical orthogonal functions and numerical simulators (Vereecken et al., 2014; Martínez et al., 2014). We firstly analyzed the range of measured $\theta_{0}$ values during the 25 surveys and then at the different humidity periods with the aim of identifying significant differences between each survey. The wet period has the highest ratio between the average rainfall and evapotranspiration (W-P, Nov. - Feb.), the dry period has the lowest ratio (D-P, Jul. - Sep.), and the spring (Sp-P, Mar. - Jun.) and the wetting-up (WUp-P, Oct.) periods have in-between values. We also defined the wet surveys as those with the highest ratios between the antecedent measured rainfall depth and the antecedent measured $E T_{0}$ and the dry surveys present the lowest ratios. Secondly, we calculated the relative topsoil water content or relative volumetric water content of the topsoil $\left(\theta_{R}, \%\right)$ that is mathematically defined as the ratio between the field measured value of $\theta_{0}$ and the estimated value of the volumetric water content at field capacity $\left(\theta_{F C}, \%\right.$ vol. $)$ :

$$
\theta_{R i}=\frac{\theta_{0 i}}{\theta_{F C i}} 100
$$

As values of $\theta_{F C}$ vary along any field and within the same soil type, this relationship relates all measured values with the potential water storage al field capacity at each observation location " $i$ ". Thus, it allows a different analysis of the spatial patterns of topsoil water content that is of interest in areas with high variability of the values of $\theta_{R i}$. This relationship was used by Talluto et al. (2008) to investigate drying processes of the soil in central Sicily (Italy) in apple orchards and also by López-Vicente et al. (2009) to analyze the spatial variation of seasonal topsoil water content in a complex agro-ecosystem (Huesca province, NE Spain) with different soil types.

In order to identify the spatial patterns of the TSWC we calculated the relative difference, $\delta_{i t}$, between the average value of $\theta_{0}$ in the whole study area at the time or survey " $t$ ", $\overline{\theta_{0 t}}$, and the specific value of $\theta_{0}$ at each observation location " $i$ ":

$$
\begin{aligned}
& \delta_{i t}=\frac{\theta_{0 i t}-\overline{\theta_{0 t}}}{\overline{\theta_{0 t}}} \\
& M R D_{i}=\frac{1}{N_{T}} \sum_{t=1}^{t=N_{T}} \delta_{i t}
\end{aligned}
$$


where $M R D_{i}$ is the mean relative difference for the location " $i$ " and $N_{T}$ is the number of observation times. And the temporal stability analysis of these differences was done calculating the standard deviation of the set $\delta_{i, 1}, \delta_{i, 2}, \ldots, \delta_{i, N_{T}}$ of relative differences at the location " $i$ " over the 25 field surveys:

$$
S D R D_{i}=\sqrt{\frac{1}{N_{T}-1} \sum_{t=1}^{t=N_{T}}\left(\delta_{i t}-M R D_{i}\right)^{2}}
$$

The value of $S D R D_{i T}$ serves as one of the measures of the temporal stability (Vachaud et al., 1985) by comparing its magnitude to the spatial variability of $M R D_{i}$. We also calculated the time stability by using the Spearman's rank, $r_{s}$, correlation coefficient. The $r_{s}$ is a nonparametric measure of statistical dependence between two variables. It assesses how well the relationship between two variables can be described using a monotonic function. It is the Pearson correlation between the ranks of one series and the ranks of another series. Because ranking linearize some of the nonlinear relationships, it is sensitive to nonlinear relationships:

$$
r_{s}=1-\frac{6 \sum_{i=1}^{n}\left(R_{i t}-R_{i t^{\prime}}\right)^{2}}{n\left(n^{2}-1\right)}
$$

where $R_{i t}$ is the rank of relative difference, $\delta_{i t}$, at time $t$ and $R_{i t}$ ' the rank of $\delta_{i t^{\prime}}$ at time $t^{\prime}$ or $t+1$, and $n$ is the number of surveys. A value of $r_{s}=1$ corresponds to identity of rank for any sites, or perfect time stability between time $t$ and $t^{\prime}$. The closer $r_{s}$ is to 1 , the more stable the spatial pattern will be. After doing these analysis, the maps for the whole study area of the $\theta_{0}$, $\theta_{R}, \delta_{i t}, M R D_{i T}$ and $S D R D_{i T}$ parameters were generated with the Kriging interpolation method (ordinary type with constant trend removal) that provides the minimum standard error and by using the $\operatorname{ArcGIS}{ }^{T M} 10.0$ software. Finally, the Pearson's correlation coefficients, $r_{p}$, between the values of $\theta_{0 i}$ and $\theta_{0 T}$ and those of the topographic, soil, hydrologic and climatic parameters were calculated:

$$
r_{p}=\frac{\sum_{i=1}^{n}\left(\theta_{0 i}-\overline{\theta_{0 t}}\right) \cdot\left(y_{i}-\bar{y}\right)}{\sqrt{\sum_{i=1}^{n}\left(\theta_{0 i}-\overline{\theta_{0 t}}\right)^{2}} \cdot \sqrt{\sum_{i=1}^{n}\left(y_{i}-\bar{y}\right)^{2}}}
$$

where $y_{i}$ is the value of the parameter.

\subsection{Topographic and soil measurements}

A high spatial resolution digital elevation model (DEM, 1 x 1 meter cell size; more details in López-Vicente et al., 2015) was used to derive the maps of slope ( $S$, \%), upslope 
contributing area $\left(A, \mathrm{~m}^{2}\right)$, curvature $(\mathrm{Cv}, 1 / 100)$, the topographic wetness index $(T W I)$ and the SAGA wetness index $(S A G A-W I)$. We also calculated several ratios with these parameters such as the average slope of the $A(U p S, \%)$, the ratio between $A$ and $S$ and between $A$ and $U p S$ and the product between $A$ and $U p S$ (Table 1). A field survey was carried out and 156 topsoil samples $(5 \mathrm{~cm}$ depth in direct correlation with the depth of the TSWC measurements) were collected in the same points where soil water content was measured (Figure 2c). Bulk density $\left(B D, \mathrm{~g} \mathrm{~cm}^{-3}\right)$ was calculated from the total sample. Then, samples were air-dried, ground, homogenized and quartered to pass through a $2 \mathrm{~mm}$ sieve and the weight of the coarse fragments was calculated (Rock, g). The volumetric water content at field capacity $\left(\theta_{F C}, \%\right.$ vol.) was measured in the laboratory by using ceramic plates in a pressure chamber. Other soil properties were measured in the laboratory (Clay, Silt and Sand content, \%) and also in field surveys, such as the unsaturated hydraulic conductivity $\left(K f-2 \mathrm{~cm}, \mathrm{~mm}\right.$ day $\left.^{-1}\right)$ with a Mini Disk Infiltrometer (Decagon Devices, Inc.) at $2 \mathrm{~cm}$ suction (Table 1). Infiltration was measured in 18 points randomly distributed across the field.

\subsection{Hydrologic and climatic parameters $\left(P, E T_{0}, R s\right)$}

We chose one parameter related with precipitation, the total rainfall depth $(P$, in $\mathrm{mm})$, and two that account the water demand, the maximum reference evapotranspiration $\left(E T_{0}, \mathrm{~mm}\right)$ and the solar radiation $\left(R s\right.$, in $\mathrm{kWh} \mathrm{m}^{-2}$ ) (Figure $\left.2 \mathrm{~d}\right)$. The first parameter was calculated from the synthetic WS whereas values of $E T_{0}$ were obtained from the Sádaba WS (automatic system of WS of the Autonomous Community of Aragón, SARGA) located $16.8 \mathrm{~km}$ south of the field. Solar radiation summarizes the different conditions of aspect and slope steepness and the different maps were calculated with SAGA 1.2 (System for Automated Geoscientific Analyses) at daily time step. Values of $R s$ were calculated without considering water vapour pressure and diffuse insolation due to the lack of the necessary information. To better analyse the effect of these parameters we calculated the cumulative values of the antecedent $P, E T_{0}$ and $R s$ before each soil water content survey from 1 day $\left(P-A 1, E T_{0}-A 1\right.$ and $\left.R s-A 1\right)$ until 14 days $\left(P-A 14, E T_{0}-A 14\right.$ and $\left.R S-A 14\right)$. The high number of TSWC measurements and soil samples and the spatial and temporal resolution of the topographic and climatic data used in this study allowed a good parameterization of the statistical analysis. 


\section{Results}

\subsection{Range of values and wet and dry periods}

For all surveys, the mean (Figure 3a), median and standard deviation (Figure 3b) of the 11,700 measurements $\left(\theta_{0 T}\right)$ were 20.4, 19.7 and $8.6 \%$ vol. respectively. Values of TSWC $\left(\theta_{0 i t}, \%\right.$ vol.) varied significantly during the 25 surveys (Figure $3 \mathrm{c}$ ). The driest survey was on September $16^{\text {th }}, 2010$ and the wettest survey was on February $23^{\text {rd }}, 2010$ with mean, median and standard deviation values of 8.2, 7.9 and $2.7 \%$ vol., and 36.8 (350\% higher than the driest survey), 37.3 and $2.3 \%$ vol., respectively. The lowest values appeared near the boundaries of the field and surrounding the outlet of one HU whereas the moistest areas appeared in the inner part of the field in the northern HUs. The range of values was minimum for the driest survey (range equals to $13 \%$ vol.), maximum on December $15^{\text {th }}, 2010$ (30\% vol.) and the average range within a survey was of $19 \%$ vol. The spatial pattern of the map of the average TSWC values agreed with the results obtained by Munoz-Pardo et al. (1990) in cultivated soils in Tunisia where they found normally distributed values of soil water content with spatial structures described by spherical semivariograms. We also obtained the minimum average standard error with the Kriging interpolator by using the spherical type instead or other methods such as the stable or Gaussian models.

In order to refine the temporal analysis we calculated the monthly average value of TSWC and analyzed these results in the four humidity periods (Figure 4). During the four months of the wet period (W-P, Nov. - Feb.) the average TSWC was $27.1 \%$ vol., whereas in the dry period (D-P, Jul. - Sep.) was 12.1\% vol. During the four months of the spring period (Sp-P, Mar. - Jun.) and the month of the wetting-up period (WUp-P, Oct.) monthly values of TSWC were quite similar between them and the average value was $18.8 \%$ vol. Garcia-Estringana et al. (2013) also found in NE Spain a clear seasonal pattern of soil water content with dry and wet conditions and drying and wetting-up periods.

The ratios between the average antecedent rainfall depth $(P-A 1, A 14)$ and the antecedent $E T_{0}\left(E T_{0}-A 1, A 14\right)$ for the 14 days before each survey were high in the wet surveys $(1.32$ on average) and low in the dry surveys (below 0.5 and 0.22 on average). From the total 25 field surveys, 13 were done during the wet period and 12 during the dry period, although 3 surveys presented wet values during the dry period and conversely 3 surveys presented dry values during the wet period. Only 6 surveys had very high values, $26.0 \%$ vol. on average and 2.1 of the $P-A / E T_{0}-A$ ratio, and 6 surveys had low values of TSWC, $12.7 \%$ vol. on average and 0.08 of the $P-A / E T_{0}-A$ ratio. The marked changes in monthly precipitation and $E T_{0}$ could explain the abrupt decrease in the TSWC in the Sp-P in relation with the W-P, and during the D-P in 
relation with the Sp-P. These decreases could also be explained by the drainage of some of the soil water accumulated in the upper horizon during the wet period and surveys beyond the topsoil and even by its percolation to the deepest horizons of the soil. This assumption is supported by the study of Celano et al. (2011) performed in southern Italy, under semi-arid climate, on Haplic Calcisols of two rainfed olive orchards. These authors evaluated the extent of water content of the deepest soil layers $(>1.0 \mathrm{~m})$ evidencing a significant water reserve in this portion of the soil.

The relative topsoil water content $\left(\theta_{R i T}, \%\right)$ presented a minimum, median and standard deviation values of 56,85 and $40 \%$, respectively. These values described an average moderate/wet scenario of soil water content in relation with this physical property of the soil. The map of the average $\theta_{R i T}$ values (Figure 5a) mirrored the map of the volumetric water content at field capacity $\left(\theta_{F C}, \%\right.$ vol.) (Figure $\left.5 \mathrm{~b}\right)$ and drew linear features. This spatial pattern agrees with the geology of the landscape where horizontal and sub-horizontal strata of sandstones with different percentages of sand and clay appear.

\subsection{Spatial patterns and temporal stability of TSWC}

\subsubsection{The spatial variability}

The minimum and maximum relative differences in the field $\left(\delta_{i=N}\right)$ were analyzed for each survey " $t$ ", obtaining in both cases decreasing values of the relative differences with increasing values of the average TSWC $\left(\overline{\theta_{0 t}}\right)$ (Figure $6 \mathrm{a}$ and $\left.6 \mathrm{~b}\right)$. Thus, the spatial variability of TSWC increased under dry conditions and more homogeneous conditions appeared in the wet surveys. The map of the mean relative difference $\left(M R D_{i T}\right)$ mirrored the spatial pattern of the average TSWC (Figure 6c). The moistest areas had the highest positive values of $M R D_{T}$ whereas the driest parts presented the lowest and negative values of $M R D_{T}$. The values of the $M R D_{i T}$ in the 156 measurement points showed a typical pattern of normal distribution (Figure 7a). Values below and above the standard deviation $(\mathrm{sd}=0.111)$ and those of the percentile 10 $\left(\mathrm{Q}_{10}=0.143\right)$ and $90\left(\mathrm{Q}_{90}=0.149\right)$ were used to identify the driest and moistest areas within the field.

\subsubsection{Temporal stability analysis}

The map of the standard deviation of the relative differences $\left(S D R D_{i T}\right)$ allowed identifying within the field those areas where the spatial changes were constant (stable) or not (low temporal stability) (Figure 6d). The combined analysis of this map with that of TSWC gave us 
information about the predictive behavior of the soil in the field and allowed us to define eight different water content zones: wettest, driest, stable and moist, stable and dry, medium stability and moist, medium stability and dry, most variable and moist, and most variable and dry. The correlation of the values of $S D R D_{i T}$ with those of the $M R D_{i T}$ (Figure $7 \mathrm{~b}$ ) and TSWC (Figure 7c) showed that the driest areas presented the highest temporal stability and the moistest areas the highest temporal variability. The short-term analysis of the temporal stability of the spatial patterns was done calculating the Spearman's rank $\left(r_{s}\right)$ and the Pearson $\left(r_{p}\right)$ correlation coefficients between the values of TSWC at each measurement point " $i$ " at time " $t$ " $\left(\theta_{0 i t}, \%\right.$ vol. $)$ and those of the relative differences at time " $t+1$ " $\left(\delta_{i t+1}\right)$ during 25 surveys (Figure 7d). We obtained similar average correlations of $0.329\left(r_{s}\right)$ and $0.371\left(r_{p}\right)$. These correlations were low though significant and suggested that the temporal stability at short-term of the spatial patterns of dry and wet areas was weak because each pattern was not a good monotone function of the previous pattern of anomalies. These results agreed with studies that indicate the presence of time stability in the soil water content when this property is repeatedly surveyed (e.g. Vachaud et al., 1985; Hu et al., 2013; Martínez et al., 2014).

\subsection{Correlation of TSWC with the topographic and soil parameters}

The Pearson's correlation coefficients, $r_{p}$, were calculated for the 25 field surveys between the 10 topographic parameters and ratios and the 9 soil factors and the TSWC values at the 156 measurement points (Table 2). The best correlations were obtained with two topographic factors: the average slope of the contributing area $(\mathrm{UpS})$ and the positive values of the curvature of the terrain (Cv.-convex); and four soil properties: rock (Rock) and silt (Silt) contents, carbonates $\left(\mathrm{CaCO}_{3}\right)$, and the volumetric content of water at field capacity (FC). The SAGA wetness index (SAGA WI) correlated better with the values of TSWC than the wellknown topographic wetness index (TWI). The bulk density (BD) and the organic matter content $(\mathrm{OM})$ were the soil properties with the worst correlations.

The worse and best average $r_{p}$ during the surveys were 0.014 and 0.334 , respectively, and during the W-P, Sp\&WUp-P and the D-P were 0.157, 0.137 and 0.159. However, the best correlations were obtained in the W-P ( 0.136 on average) in 8 of the 11 topographic factors and ratios, and the best correlations were obtained in the D-P ( 0.219 on average) in 6 of the 8 soil properties. In order to refine the correlation analysis of the average values of TSWC we calculated the average water content in each hydrological unit (HU) and those of the main topographic and soil factors (Table 3). We obtained high correlations with the parameters of 
FC $\left(r_{p}=0.798\right), \operatorname{UpS}\left(r_{p}=0.555\right)$ and Cv.-convex $\left(r_{p}=0.516\right)$ and moderate with $\mathrm{CaCO}_{3}$ $\left(r_{p}=0.361\right)$, whereas correlations with Rock and Silt were weak.

Finally, we calculated the values of TSWC, $M R D_{i T}$ and $S D R D_{i T}$ and of the main topographic and soil parameters for the different water content zones (Table 4). The wettest areas (percentile 10, $\mathrm{Q}_{10}$ ) had the lowest values of rocks and $\mathrm{CaCO}_{3}$ and the highest of silt and water content at field capacity. Conversely, the driest soils presented high contents of rocks and $\mathrm{CaCO}_{3}$ and low of silt and water content at field capacity and were located in areas with the highest values of positive curvature (Cv.-convex) of the terrain. The most stable areas $\left(S D R D_{i T}-\mathrm{Q}_{10}\right)$ presented the lowest values of the average upslope steepness $(\mathrm{UpS})$ and were mainly dry. The areas with medium values of temporal stability of soil water content were mainly under moist conditions and presented intermediate values of the topographic and soil factors. Soils with the highest temporal variability $\left(S D R D_{i T}-\mathrm{Q}_{90}\right)$ were mainly moist with high values of UpS and Cv.-convex though average values of the topographic and soil factors.

\subsection{Climatic influence on the values of TSWC}

The Pearson's correlation coefficients, $r_{p}$, between the average values of TSWC in each field survey and those of the antecedent rainfall $(P-A)$, evapotranspiration $\left(E T_{0}-A\right)$ and solar radiation $(R s-A)$ were calculated for the antecedent period from 1 day until 14 days (Figure 8). Correlations markedly changed when the wet, dry, spring and wetting-up periods were considered and even when the wet and dry surveys were analysed. Correlations were satisfactory with the values of $P-A$ and the ratio between $P-A$ and $E T_{0}-A$. For the wet period and wet surveys the best correlations were obtained with the values of $P-A$ and $E T_{0}-A$ between 2 and 3 days, whereas for the dry period and dry surveys the best correlations appeared with an antecedent period between 6 and 7 days. Weak correlations were found with the values of $R s-A$. The different correlations of the hydrological response of the soil to the antecedent values of the hydrologic and climatic parameters agreed with the results presented by Palleiro et al. (2014) in NE Spain where correlations between runoff yield and coefficients markedly varied for the different antecedent periods. These results described a complex system where the antecedent $P, E T_{0}$ and $R s$ can only predict a part of the water storage processes in the topsoil.

\section{Further research}

In order to refine our knowledge about topsoil water content fields and their temporal variability we will pay attention to the penetration resistance of the topsoil that has a direct 
relationship with the TSWC. Modelling approaches of runoff during the different types of rainfall events (depth and intensity) and of the overland flow connectivity will be also considered in future studies. A very high density survey of infiltration rates of the topsoil at different water pressures could offer valuable data to understand the soil water content dynamics. Finally, the use of values of actual evapotranspiration instead of those of $E T_{0}$ will refine the assessment of the water balance in the soil especially in summer when water stress is very high for Mediterranean crops and plants.

\section{Conclusions}

Despite the significant variability of topsoil water content (TSWC) during the 25 field surveys four humidity periods could be described: wet (Nov. - Feb.), spring (Mar. - Jun.), dry (D-P, Jul. - Sep.) and wetting-up (Oct.). The variability within each period was also described and 3 surveys presented wet values during the dry period and 3 surveys dry values during the wet period. Under dry conditions the spatial variability increased whereas more homogeneous conditions appeared in the wet surveys. The map of the relative TSWC mirrored the spatial pattern of the volumetric water content at field capacity and draw linear patterns due to the geological structure of the strata.

At short-term there was not a good temporal stability of the spatial patterns of both the water content and the value changes. However, the combined analysis of the map of the standard deviation of the relative differences and the map of TSWC allowed defining eight water content zones: wettest, driest, stable and moist, stable and dry, medium stability and moist, medium stability and dry, most variable and moist, and most variable and dry. The different zones presented different values of the soil and topographic factors that explain the different temporal stability of the relative differences in TSWC.

Satisfactory correlations were only obtained with 2 of the 10 topographic parameters and ratios (average slope of the contributing area and convexity) and 4 of the 9 soil properties (rock, silt and carbonates contents, and the volumetric content of water at field capacity) highlighting the complexity of the processes involved and the difficulty for stablishing a good predictive model for the TSWC. The best correlations of these factors were obtained in the wet period. The values of the antecedent rainfall and evapotranspiration showed a different time response with the water content in the wet and dry periods obtaining the best correlations between 2 and 3 days and between 6 and 7 days, respectively. Besides the complexity of the spatial patterns of TSWC and their temporal changes we satisfactorily identified and characterized different humidity areas in the field and thus our hypothesis was validated. 


\section{Acknowledgements}

This research was funded by the project "Erosion and redistribution of soils and nutrients in Mediterranean agroecosystems: radioisotopic tracers of sources and sinks and modelling of scenarios (EROMED) (CGL2011-25486/BTE)" of the Spanish Ministry of Economy and Competitiveness. We especially thank Dr. Javier Machín for giving up the field where the research of this article has been done. We are also grateful for the comments and suggestions from two anonymous reviewers and from the Editor of the journal who have helped to improve the manuscript.

\section{References}

Aboudrare, A., Debaeke, P., Bouaziz, A., Chekli, H., 2006. Effects of soil tillage and fallow management on soil water storage and sunflower production in a semi-arid Mediterranean climate. Agricultural Water Management 83(3), 183-196.

Ackerson, J.P., Morgan, C.L.S., Everett, M.E., McInnes, K.J., 2014. The Role of Water Content in Electrical Resistivity Tomography of a Vertisol. Soil Science Society of America Journal 78(5), 1552-1562.

Baskan, O., Kosker, Y., Erpul, G., 2013. Spatial and temporal variation of moisture content in the soil profiles of two different agricultural fields of semi-arid region. Environmental Monitoring and Assessment 185(12), 10441-10458.

Bewick, L.S., Young, F.L., Alldredge, J.R., Young, D.L., 2008. Agronomics and economics of no-till facultative wheat in the Pacific Northwest, USA. Crop Protection 27(6), 932-942.

Cammeraat, E.L.H., Cerdà, A., Imeson, A.C., 2010. Ecohydrological adaptation of soils following land abandonment in a semi-arid environment. Ecohydrology 3(4), 421-430.

Celano, G., Palese, A.M., Ciucci, A., Martorella, E., Vignozzi, N., Xiloyannis, C., 2011. Evaluation of soil water content in tilled and cover-cropped olive orchards by the geoelectrical technique. Geoderma 163(3-4), 163170.

Espejo, A., Giráldez, J.V., Vanderlinden, K., Taguas, E.V., Pedrera, A., 2014. A method for estimating soil water diffusivity from moisture profiles and its application across an experimental catchment. Journal of Hydrology 516, 161-168.

Fernández-Ugalde, O., Virto, I., Bescansa, P., Imaz, M.J., Enrique, A., Karlen, D.L., 2009. No-tillage improvement of soil physical quality in calcareous, degradation-prone, semiarid soils. Soil and Tillage Research 106(1), 29-35.

Gabrielle, B., Laville, P., Hénault, C., Nicoullaud, B., Germon, J.C., 2006. Simulation of nitrous oxide emissions from wheat-cropped soils using CERES. Nutrient Cycling in Agroecosystems 74(2), 133-146.

Garcia-Estringana, P., Latron, J., Llorens, P., Gallart, F., 2013. Spatial and temporal dynamics of soil moisture in a Mediterranean mountain area (Vallcebre, NE Spain). Ecohydrology 6(5), 741-753.

García-Ruiz, J.M., López-Moreno, J.I., Vicente-Serrano, S.M., Lasanta-Martínez, T., Beguería, S., 2011. Mediterranean water resources in a global change scenario. Earth-Science Reviews 105(3-4), 121-139. 
Gomi, T., Sidle, R.C., Ueno, M., Miyata, S., Kosugi, K., 2008. Characteristics of overland flow generation on steep forested hillslopes of central Japan. Journal of Hydrology 361(3-4), 275-290.

Hu, W., Tallon, L.K., Biswas, A., Si, B.C., 2013. Time Stability of Soil Water Content (Chapter 3). In: Advances in Agrophysical Research. Licensee InTech, 47-80, http://dx.doi.org/10.5772/52469.

Lampurlanés, J., Angás, P., Cantero-Martínez, C., 2002. Tillage effects on water storage during fallow, and on barley root growth and yield in two contrasting soils of the semi-arid Segarra region in Spain. Soil and Tillage Research 65(2), 207-220.

Lawrence, P.A., Radford, B.J., Thomas, G.A., Sinclair, D.P., Key, A.J., 1994. Effect of tillage practices on wheat performance in a semi-arid environment. Soil and Tillage Research 28(3-4), 347-364.

López, M.V., Arrúe, J.L., Sánchez-Girón, V., 1996. A comparison between seasonal changes in soil water storage and penetration resistance under conventional and conservation tillage systems in Aragon. Soil and Tillage Research 37(4), 251-271.

López-Vicente, M., Navas, A., Machín, J., 2008. Identifying erosive periods by using RUSLE factors in mountain fields of the Central Spanish Pyrenees. Hydrology and Earth System Sciences 12(2), 523-535.

López-Vicente, M., Navas, A., Machín, J., 2009. Effect of physiographic conditions on the spatial variation of seasonal topsoil moisture in Mediterranean soils. Australian Journal of Soil Research 47(5), $498-507$.

López-Vicente, M., Quijano, L., Gaspar, L., Palazón, L., Navas, A., 2015. Severe soil erosion during a three-day exceptional rainfall event: combining modelling and field data for a fallow cereal field. Hydrological Processes 29(10), 2358-2372.

Martínez, G., Pachepsky, Y.A., Vereecken, H., 2014. Temporal stability of soil water content as affected by climate and soil hydraulic properties: A simulation study. Hydrological Processes 28(4), 1899-1915.

Milly, P.C.D., Dunne, K.A., Vecchia, A.V., 2005. Global pattern of trends in streamflow and water availability in a changing climate. Nature 438(7066), 347-350.

Moret, D., Braud, I., Arrúe, J.L., 2007. Water balance simulation of a dryland soil during fallow under conventional and conservation tillage in semiarid Aragon, Northeast Spain. Soil and Tillage Research 92(12), 251-263.

Munoz-Pardo, J., Ruelle, P., Vauclin, M., 1990. Spatial variability of an agricultural field: Geostatistical analysis of soil texture, soil moisture and yield components of two rainfed crops. Catena 17(4-5), 369-381.

Navas, A., Machín, J., Beguería, S., López-Vicente, M., Gaspar, L., 2008. Soil properties and physiographic factors controlling the natural vegetation re-growth in a disturbed catchment of the Central Spanish Pyrenees. Agroforestry Systems 72(3), 173-185.

Oliver, Y.M., Robertson, M.J., Weeks, C., 2010. A new look at an old practice: Benefits from soil water accumulation in long fallows under Mediterranean conditions. Agricultural Water Management 98(2), 291300 .

Orfánus, T., Eitzinger, J., 2010. Factors influencing the occurrence of water stress at field scale. Ecohydrology $3(4), 478-486$.

Pala, M., Ryan, J., Zhang, H., Singh, M., Harris, H.C., 2007. Water-use efficiency of wheat-based rotation systems in a Mediterranean environment. Agricultural Water Management 93(3), 136-144. 
Palese, A.M., Vignozzi, N., Celano, G., Agnelli, A.E., Pagliai, M., Xiloyannis, C., 2014. Influence of soil management on soil physical characteristics and water storage in a mature rainfed olive orchard. Soil and Tillage Research 144, 96-109.

Palleiro, L., Rodríguez-Blanco, M.L., Taboada-Castro, M.M., Taboada-Castro, M.T., 2014. Hydrological response of a humid agroforestry catchment at different time scales. Hydrological Processes 28(4), 16771688.

Pathak, P., Sudi, R., Wani, S.P., Sahrawat, K.L., 2013. Hydrological behavior of Alfisols and Vertisols in the semi-arid zone: Implications for soil and water management. Agricultural Water Management 118, $12-21$.

Penna, D., van Meerveld, H.J., Oliviero, O., Zuecco, G., Assendelft, R.S., Dalla Fontana, G., Borga, M., 2015. Seasonal changes in runoff generation in a small forested mountain catchment. Hydrological Processes 29(8), 2027-2042.

Qin, W., Chi, B., Oenema, O., 2013. Long-term monitoring of rainfed wheat yield and soil water at the loess plateau reveals low water use efficiency. PLoS ONE 8(11), e78828.

Quijano, L., Chaparro, M.A.E., Marié, D.C., Gaspar, L., Navas, A., 2014. Relevant magnetic and soil parameters as potential indicators of soil conservation status of Mediterranean agroecosystems. Geophysical Journal International 198, 1805-1817.

Quijano, L., López-Vicente, M., Gaspar, L., Machín, J., Navas, A., 2013. Modelling soil redistribution in a hydrologically defined crop field with WATEM/SEDEM. Geophysical Research Abstracts 15, EGU20135413.

Ramos, M.E., Robles, A.B., Sánchez-Navarro, A., González-Rebollar, J.L., 2011. Soil responses to different management practices in rainfed orchards in semiarid environments. Soil and Tillage Research 112(1), 8591.

Ryan, J., Monem, M.A., Amri, A., 2009. Nitrogen fertilizer response of some barley varieties in semi-arid conditions in Morocco. Journal of Agricultural Science and Technology 11(2), 227-236.

Saue, T., Kadaja, J., 2014. Water limitations on potato yield in Estonia assessed by crop modelling. Agricultural and Forest Meteorology 194, 20-28.

Soldevilla-Martinez, M., Martin-Lammerding, D., Tenorio, J.L., Walter, I., Quemada, M., Lizaso, J.I., 2013. Simulating improved combinations tillage-rotation under dryland conditions. Spanish Journal of Agricultural Research 11(3), 820-832.

Talluto, G., Farina, V., Volpe, G., Lo Bianco, R., 2008. Effects of partial rootzone drying and rootstock vigour on growth and fruit quality of 'Pink Lady' apple trees in Mediterranean environments. Australian Journal of Agricultural Research 59(9), 785-794.

Ursino, N., Cassiani, G., Deiana, R., Vignoli, G., Boaga, J., 2014. Measuring and modeling water-related soilvegetation feedbacks in a fallow plot. Hydrology and Earth System Sciences 18(3), 1105-1118.

Vachaud, G., Passerat De Silans, A., Balabanis, P., Vauclin, M., 1985. Temporal Stability of Spatially Measured Soil Water Probability Density Function. Soil Science Society of America Journal 49, 822-828.

Vereecken, H., Huisman, J.A., Pachepsky, Y., Montzka, C., van der Kruk, J., Bogena, H., Weihermüller, L., Herbst, M., Martinez, G., Vanderborght, J., 2014. On the spatio-temporal dynamics of soil moisture at the field scale. Journal of Hydrology 516, 79-96. 
Viola, F., Valerio-Noto, L., Cannarozzo, M., Loggia, G.L., Porporato, A., 2012. Olive yield as a function of soil moisture dynamics. Ecohydrology 5(1), 99-107.

Yu, Y.-C., Zhang, G.-H., Geng, R., Li, Z.-W., 2014. Temporal variation in soil rill erodibility to concentrated flow detachment under four typical croplands in the Loess Plateau of China. Journal of Soil and Water Conservation 69(4), 352-363.

Figure 1. (a) Overland flow pattern of the La Reina catchment (lower part) with the boundaries of the field and its four hydrological units, (b) location of the study area in the Ebro river basin (NE Spain), and (c) picture of the field under fallow conditions.
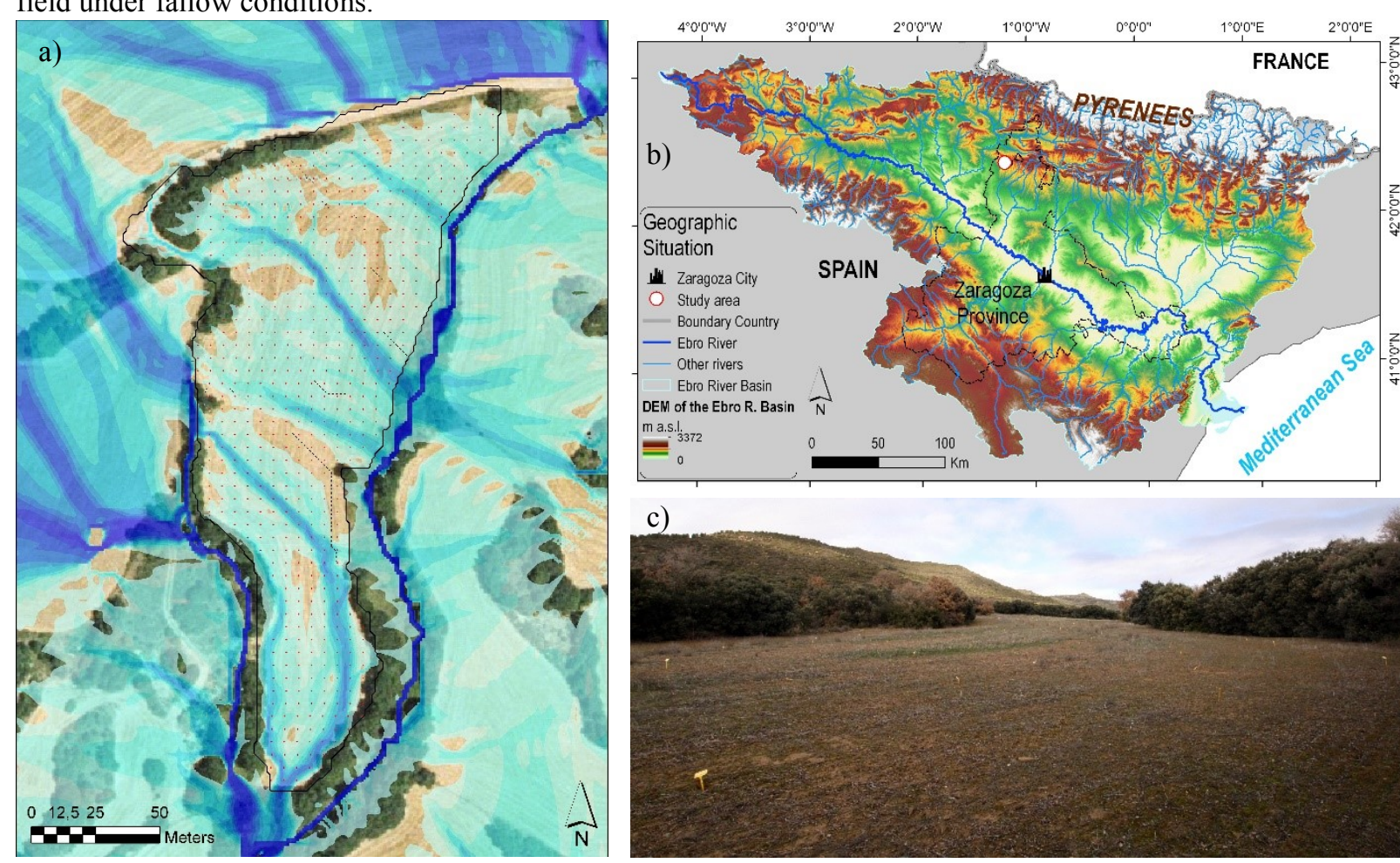

c)

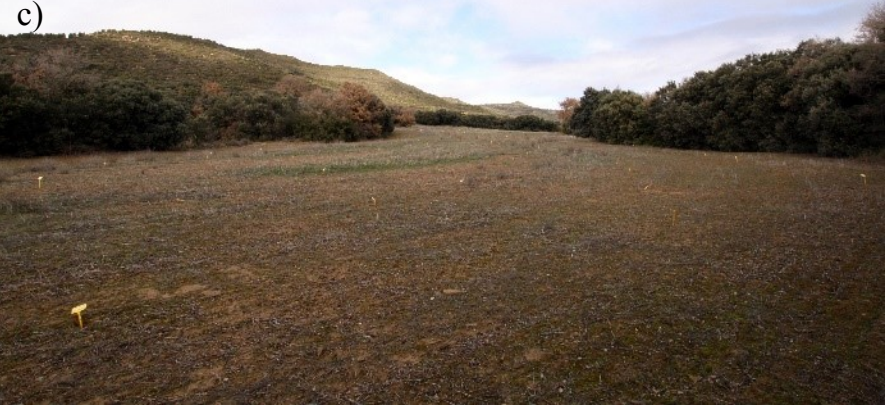


Figure 2. (a), Pictures of the soil profile in the upper $6 \mathrm{~cm}$ and (b) of the frequency-domain probe used to measure the TSWC, (c) map of the field showing the location of the measurement points and of the 156 topsoil samples, (d) monthly rainfall depth $(P, \mathrm{~mm})$ at the synthetic weather station, and monthly evapotranspiration $\left(E T_{0}, \mathrm{~mm}\right)$, maximum rainfall intensity $\left(I_{30}, \mathrm{~mm} \mathrm{~h}^{-1}\right)$, number of rainfall events $(e, \mathrm{n})$ and erosive events $(e e, \mathrm{n})$ at the Uncastillo weather station.
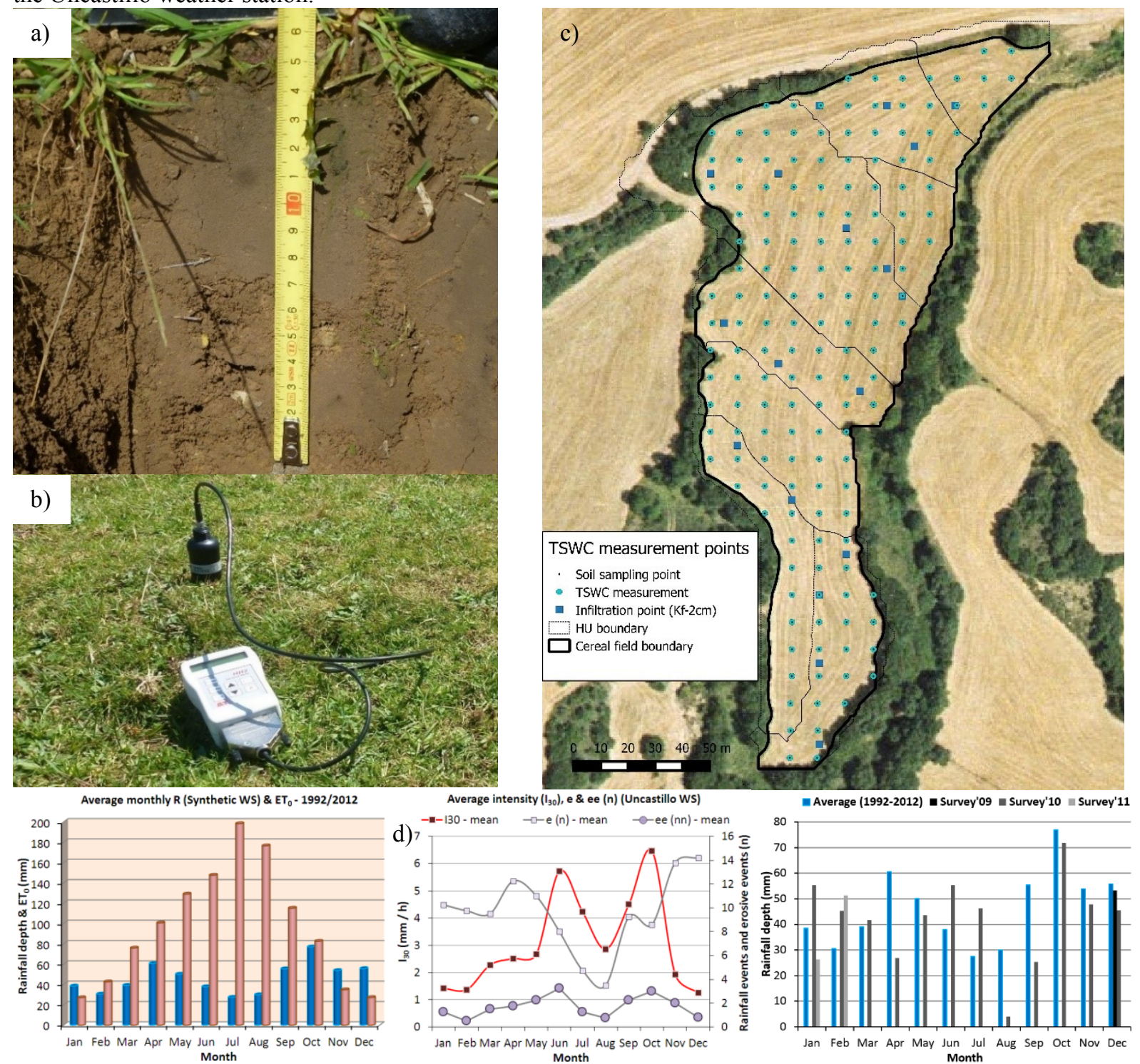
Figure 3. Maps of the average (a) and standard deviation (b) values of TSWC $\left(\theta_{0 i T}\right)$, and boxplots of the $\theta_{0 i t}$ values in the 156 " $i$ " measurement points during the 25 " $t$ " field surveys (c).
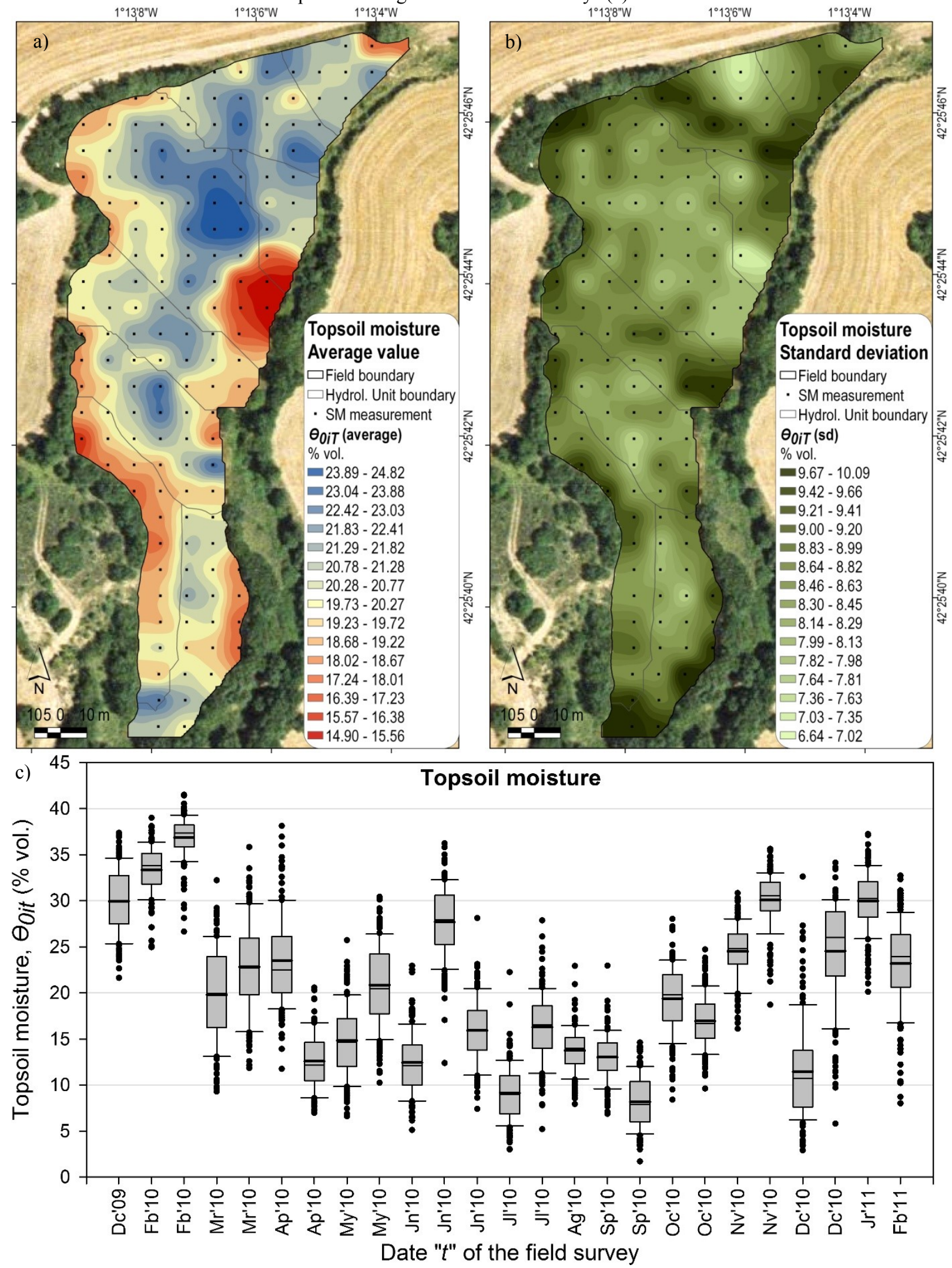
Figure 4. Average monthly value of TSWC $\left(\theta_{0}\right)$ and monthly median value of the ratio between the antecedent rainfall depth $(P-A)$ and maximum reference evapotranspiration $\left(E T_{0}-A\right)$. The wet (W-P), spring (Sp-P), dry (D$\mathrm{P})$ and wetting-up (WUp-P) periods are showed in the graph.

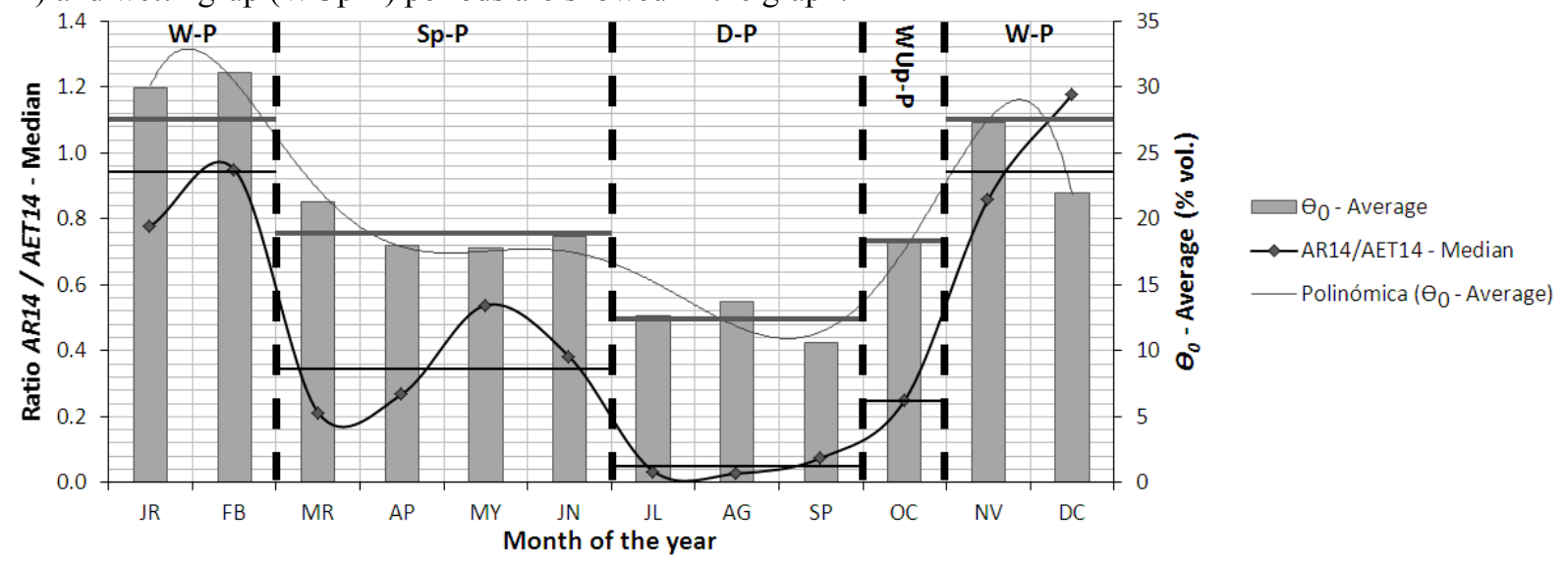

Figure 5. Maps of the average relative topsoil water content $\theta_{R i T}$ (a) and of the volumetric water content at field capacity $\theta_{F C i}(\mathrm{~b})$.

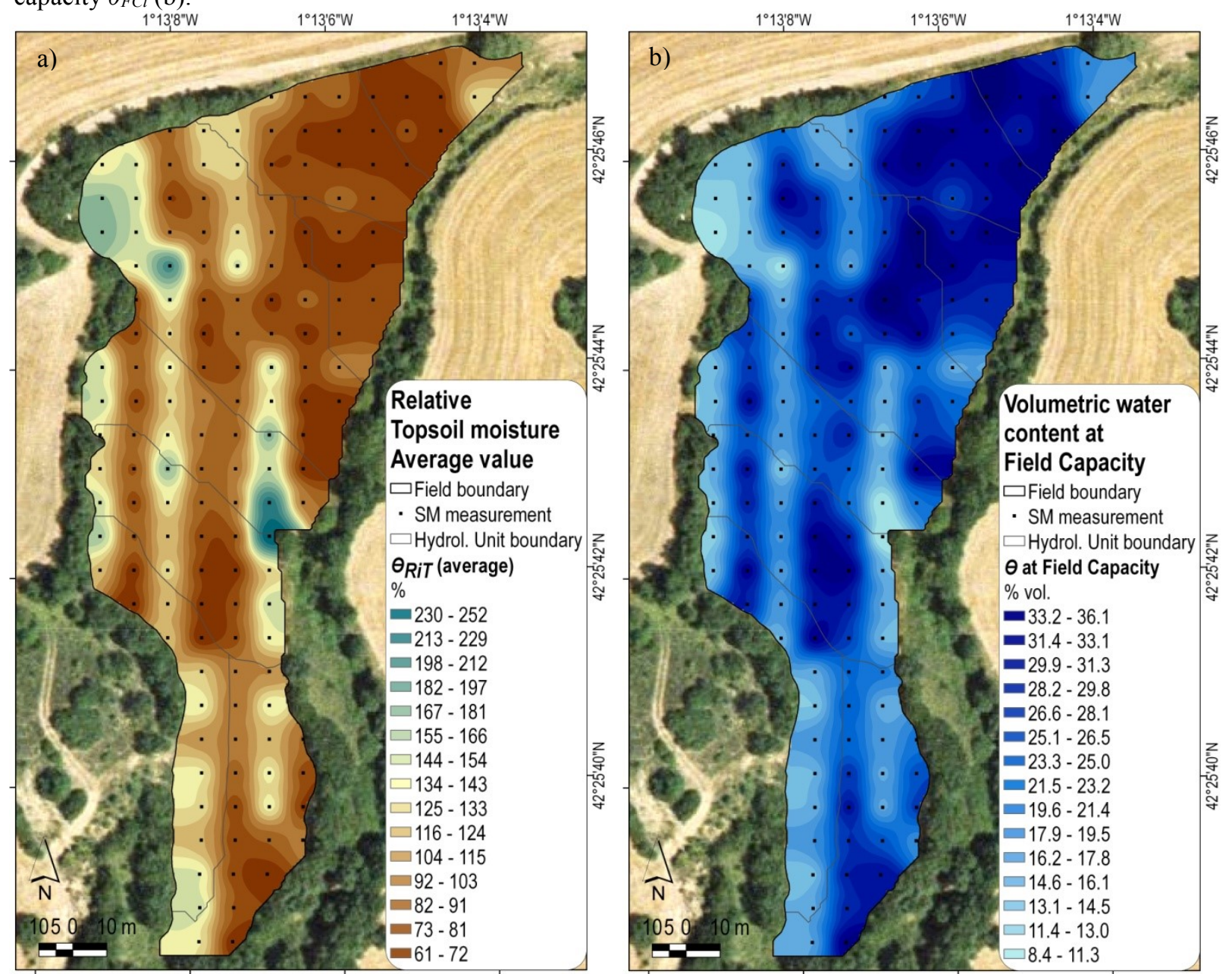


Figure 6. Correlation between the average TSWC and the minimum (a) and maximum (b) relative difference at each survey. Maps of the mean relative difference $\left(M R D_{i T}\right)(\mathrm{c})$ and of the standard deviation of the relative difference $\left(S D R D_{i T}\right)(\mathrm{d})$ of the $\theta_{0 i}$ values after the 25 field surveys.
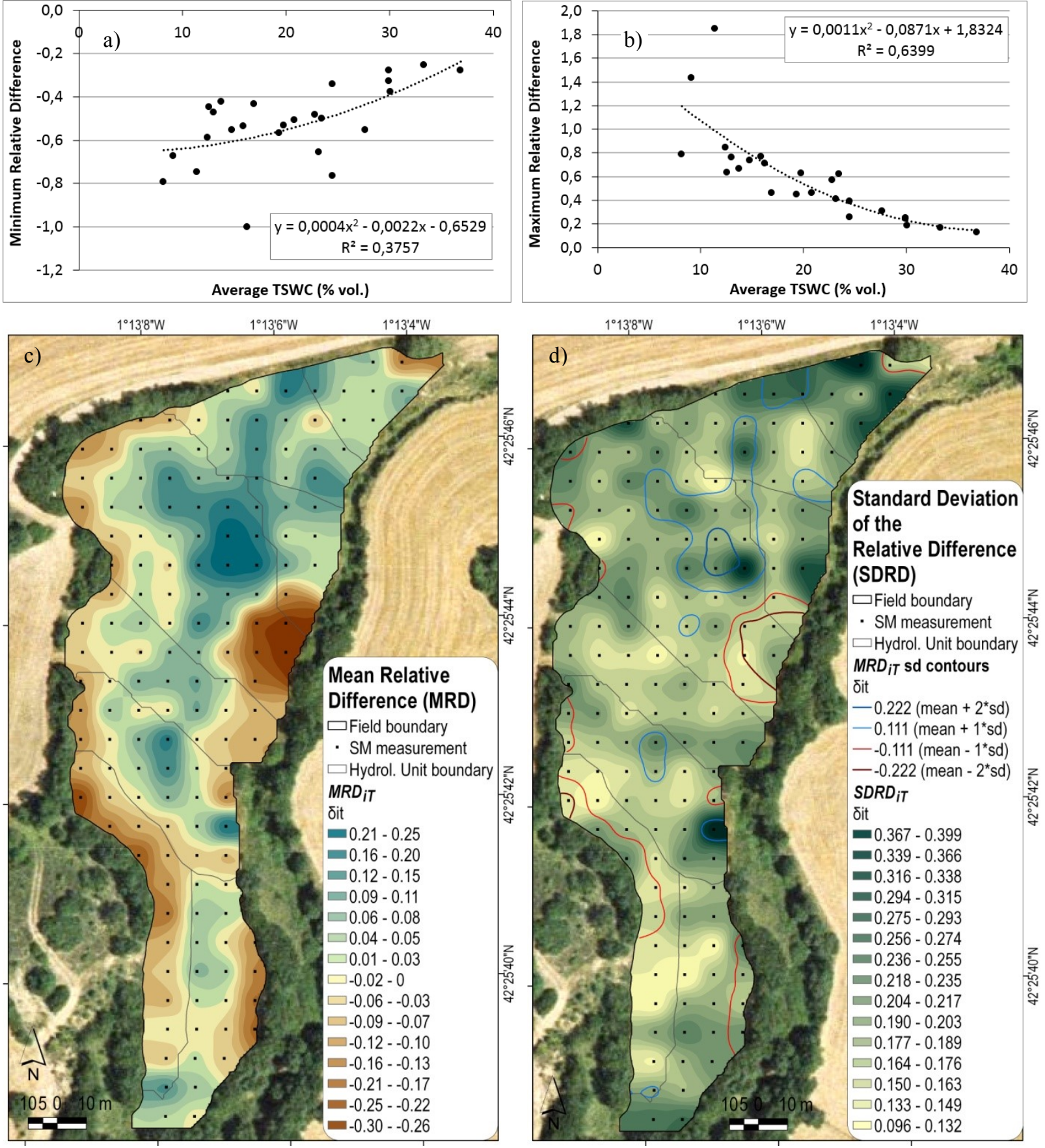
Figure 7. Normal distribution of the average values of the mean relative differences in the measurement points $\left(M R D_{i T}\right)$ (a), correlation of the values of $S D R D_{i T}$ with those of the $M R D_{i T}$ (b) and TSWC (c), and Spearman's rank and Pearson correlation coefficients between the values of the TSWC at each point at time $t$ and those of the relative differences $\left(\delta_{i}\right)$ at time $t+1$ during the 25 field surveys.
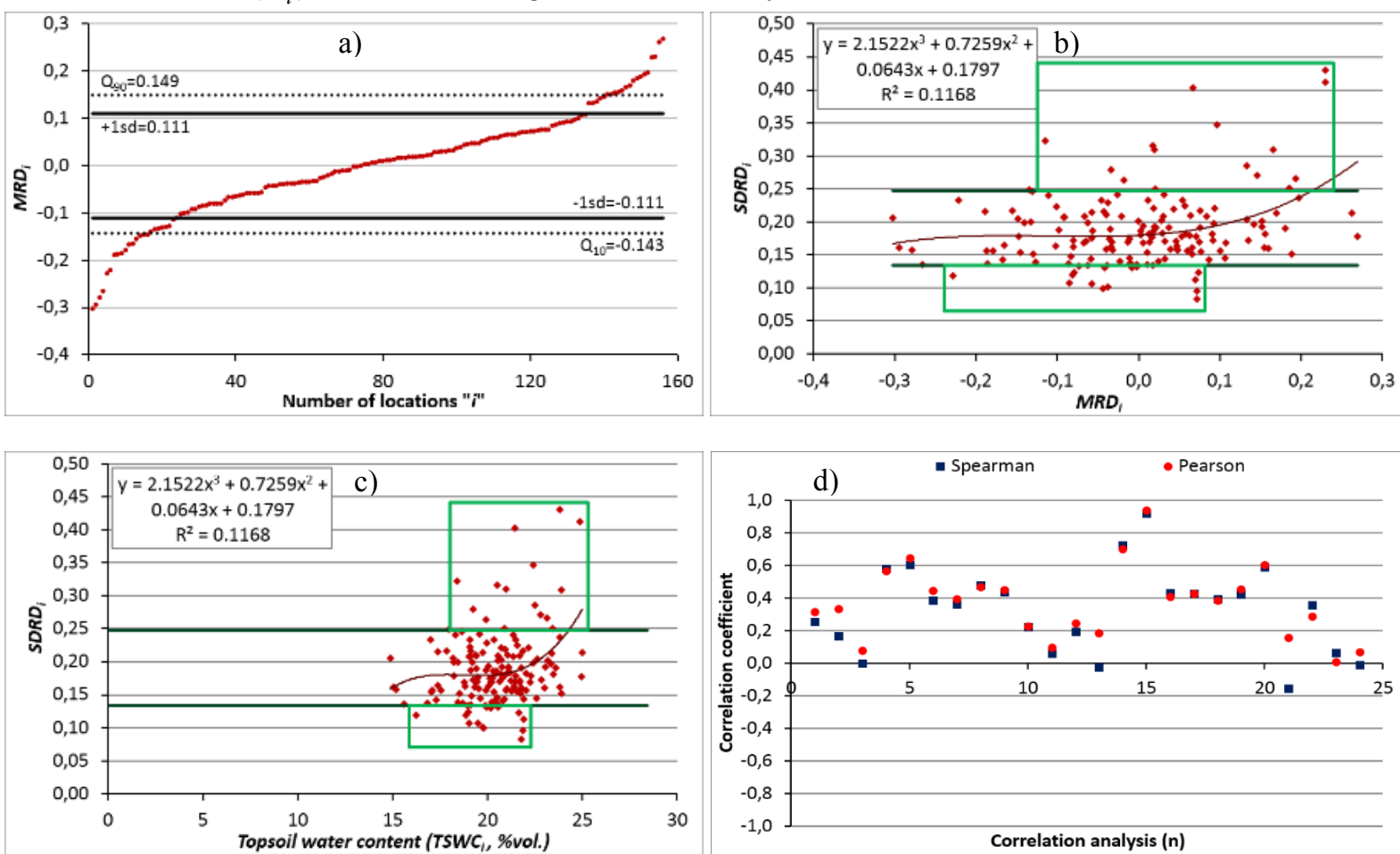
Figure 8 . The Pearson's correlation coefficients, $R_{p}$, between the average values of TSWC and those of the antecedent rainfall $(P-A)$, evapotranspiration $\left(E T_{0}-A\right)$ and solar radiation $(R s-A)$
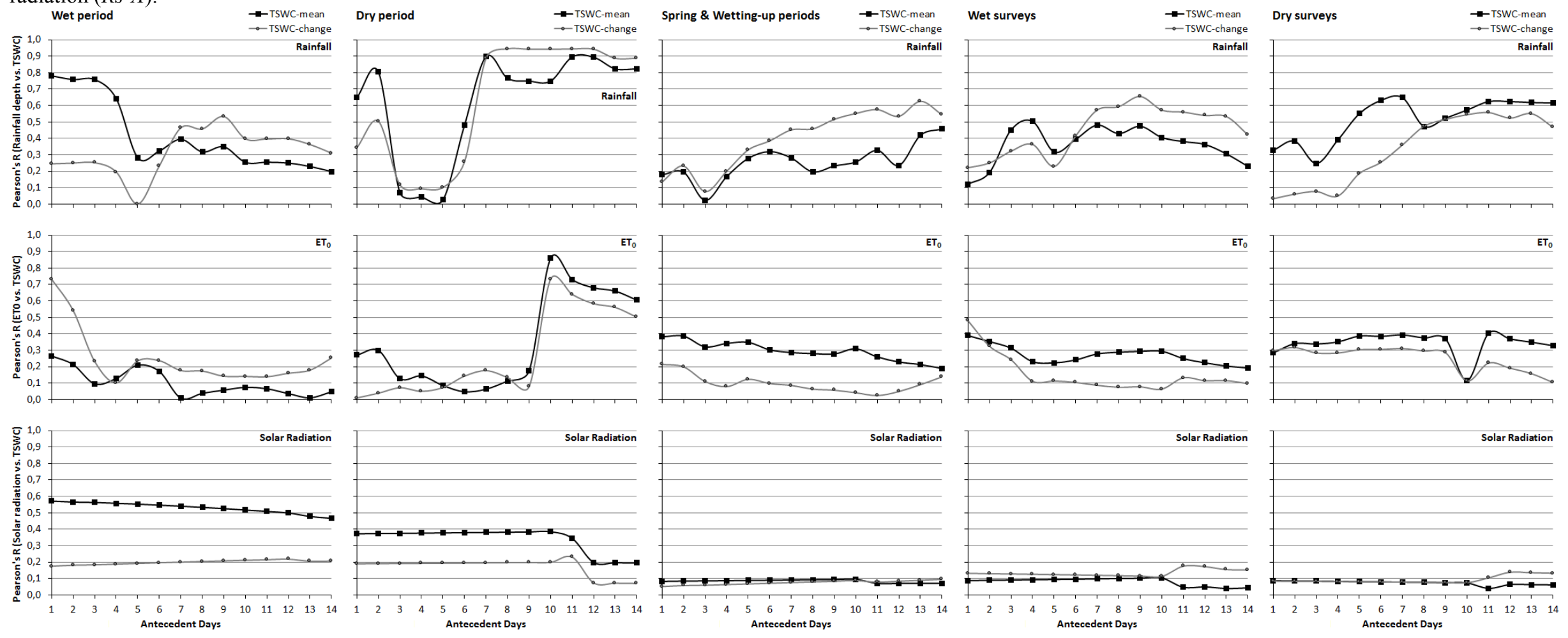
Table 1. Range of values of the topographic and topsoil parameters correlated with those of TSWC.

\begin{tabular}{|c|c|c|c|c|c|}
\hline \multicolumn{2}{|c|}{ Factor } & \multicolumn{4}{|c|}{${ }^{*}$ Range of values } \\
\hline Type & Name & $\min$ & mean & $\max$ & $\mathrm{sd}$ \\
\hline \multirow[t]{8}{*}{ Soil } & Rock (\% weight) & 0 & 3 & 38 & 5 \\
\hline & Clay (\%) & 25 & 36 & 69 & 7 \\
\hline & Silt (\%) & 26 & 52 & 62 & 6 \\
\hline & $\mathrm{BD}\left(\mathrm{g} \mathrm{cm}^{-3}\right)$ & 0.49 & 1.18 & 1.54 & 0.15 \\
\hline & $\mathrm{OM}(\%)$ & 0.5 & 1.8 & 3.2 & 0.5 \\
\hline & $\mathrm{CaCO}_{3}(\%)$ & 29 & 38 & 46 & 3 \\
\hline & FC (\% vol. $)$ & 7 & 23 & 38 & 8 \\
\hline & $\mathrm{K}_{\mathrm{f}-2 \mathrm{~cm}}\left(\mathrm{~mm} \mathrm{day}^{-1}\right)$ & 12.8 & 57.9 & 153.6 & 43.2 \\
\hline \multirow[t]{7}{*}{ Topography } & $\mathrm{A}\left(\mathrm{m}^{2}\right)$ & 1 & 60 & 1011 & 144 \\
\hline & $\mathrm{S}(\%)$ & 1 & 9 & 37 & 5 \\
\hline & $\mathrm{UpS}(\%)$ & 3 & 11 & 50 & 7 \\
\hline & A / S (ratio) & 0 & 11 & 272 & 33 \\
\hline & A / UpS (ratio) & 0 & 7 & 124 & 16 \\
\hline & $A \cdot \mathrm{UpS}$ (product) & 3 & 618 & 13673 & 1623 \\
\hline & Cv. $(1 / 100)$ & -9.2 & -0.4 & 7.5 & 1.9 \\
\hline \multirow[t]{3}{*}{ Overland flow } & TWI (ratio) & 3.5 & 8.1 & 14.7 & 2.2 \\
\hline & SAGA-WI (ratio) & 2.3 & 6.1 & 9.8 & 1.6 \\
\hline & HU (8 units) & ---- & ---- & ---- & ---- \\
\hline
\end{tabular}

*Range of values at the sampling points; BD: bulk density; OM: organic matter; FC: volumetric water content at field capacity; $\mathrm{K}_{\mathrm{f}-2 \mathrm{~cm}}$ : Topsoil non-saturated infiltration rate; A: area; S: slope steepness; UpS: average upslope steepness; Cv.: curvature; TWI: topographic wetness index; SAGA-WI: SAGA GIS software wetness index; HU: hydrological unit.

Table 2. Pearson's correlation coefficients $\left(r_{p}\right)$ between the topographic and soil parameters and the values of TSWC during the 25 field surveys at the 156 measurement points.

\begin{tabular}{|c|c|c|c|c|c|c|c|}
\hline \multicolumn{2}{|c|}{ Factor } & \multicolumn{6}{|c|}{ Correlation coefficient } \\
\hline Type & Name & Worse* & Average* & Best* & $\begin{array}{l}\text { Wet } \\
\text { period }\end{array}$ & $\begin{array}{c}\text { Spring \& } \\
\text { wetting-up period }\end{array}$ & $\begin{array}{c}\text { Dry } \\
\text { period }\end{array}$ \\
\hline \multirow[t]{9}{*}{ Soil } & Rock (\% weight) & 0.072 & 0.227 & 0.442 & 0.220 & 0.212 & 0.271 \\
\hline & Clay (\%) & 0.012 & 0.277 & 0.454 & 0.287 & 0.256 & 0.307 \\
\hline & Silt $(\%)$ & 0.007 & 0.282 & 0.453 & 0.287 & 0.264 & 0.313 \\
\hline & Clay + Silt (\%) & 0.025 & 0.220 & 0.383 & 0.242 & 0.193 & 0.240 \\
\hline & $\mathrm{BD}\left(\mathrm{g} \mathrm{cm}^{-3}\right)$ & 0.006 & 0.076 & 0.216 & 0.047 & 0.092 & 0.093 \\
\hline & OM $(\%)$ & 0.007 & 0.136 & 0.321 & 0.122 & 0.142 & 0.149 \\
\hline & $\mathrm{CaCO}_{3}(\%)$ & 0.009 & 0.119 & 0.422 & 0.163 & 0.093 & 0.100 \\
\hline & FC ( $\%$ vol. $)$ & 0.024 & 0.203 & 0.354 & 0.150 & 0.212 & 0.280 \\
\hline & $\mathrm{K}_{\mathrm{f}-2 \mathrm{~cm}}\left(\mathrm{~mm} \mathrm{day}^{-1}\right)$ & 0.002 & 0.120 & 0.280 & 0.132 & 0.109 & 0.120 \\
\hline \multirow[t]{9}{*}{ Topography } & $\mathrm{A}\left(\mathrm{m}^{2}\right)$ & 0.014 & 0.096 & 0.229 & 0.137 & 0.076 & 0.065 \\
\hline & S (\%) & 0.002 & 0.124 & 0.297 & 0.143 & 0.119 & 0.101 \\
\hline & $\mathrm{UpS}(\%)$ & 0.042 & 0.170 & 0.439 & 0.161 & 0.163 & 0.201 \\
\hline & A / S (ratio) & 0.007 & 0.103 & 0.272 & 0.130 & 0.088 & 0.088 \\
\hline & A / UpS (ratio) & 0.007 & 0.110 & 0.262 & 0.157 & 0.091 & 0.067 \\
\hline & $\mathrm{A} \cdot \mathrm{UpS}$ (product) & 0.002 & 0.071 & 0.193 & 0.094 & 0.059 & 0.058 \\
\hline & Cv. (1/100) [All] & 0.001 & 0.055 & 0.203 & 0.066 & 0.049 & 0.051 \\
\hline & Cv. $(1 / 100)[<0]$ & 0.008 & 0.156 & 0.410 & 0.155 & 0.158 & 0.154 \\
\hline & Cv. $(1 / 100)[>0]$ & 0.015 & 0.188 & 0.449 & 0.101 & 0.164 & 0.395 \\
\hline \multirow{2}{*}{$\begin{array}{l}\text { Overland } \\
\text { flow }\end{array}$} & TWI (ratio) & 0.001 & 0.118 & 0.260 & 0.177 & 0.100 & 0.052 \\
\hline & SAGA-WI (ratio) & 0.021 & 0.126 & 0.337 & 0.177 & 0.106 & 0.078 \\
\hline
\end{tabular}

*: During the 25 field survey; BD: bulk density; OM: organic matter; FC: volumetric water content at field capacity; $\mathrm{K}_{\mathrm{f}-2 \mathrm{~cm}}$ : Topsoil non-saturated infiltration rate; A: area; S: slope steepness; UpS: average upslope steepness; Cv.: curvature; TWI: topographic wetness index; SAGA-WI: SAGA GIS software wetness index. 
Table 3. Average values of TSWC (after the 25 field surveys, $\theta_{0 i T}$ ) in the eight hydrological units (HU) and those of the topographic and soil parameters with the highest Pearson's coefficients of correlation.

\begin{tabular}{|c|c|c|c|c|c|c|c|c|c|}
\hline \multicolumn{2}{|c|}{$\mathrm{HU}$} & \multicolumn{2}{|c|}{ Topography } & \multicolumn{4}{|c|}{ Soil } & \multicolumn{2}{|c|}{ TSWC } \\
\hline \multirow[t]{2}{*}{ Number } & \multirow[t]{2}{*}{ Name } & $\mathrm{UpS}$ & Cv. [+] & Rock & Silt & $\mathrm{CaCO}_{3}$ & $\mathrm{FC}$ & mean & $\mathrm{sd}$ \\
\hline & & $(\%)$ & $(1 / 100)$ & $(\%)$ & $(\%)$ & $(\%)$ & (\% vol.) & \multicolumn{2}{|c|}{ (\% vol.) } \\
\hline 1 & $1 \mathrm{~N}$ & 20.1 & 1.6 & 1.9 & 47.4 & 37.0 & 27.8 & 20.8 & 8.6 \\
\hline 2 & $1 \mathrm{EG}$ & 12.8 & 0.7 & 1.5 & 55.1 & 37.6 & 27.4 & 21.5 & 8.7 \\
\hline 3 & $1 \mathrm{~S}$ & 10.1 & 1.0 & 5.1 & 50.8 & 38.6 & 28.8 & 21.0 & 8.2 \\
\hline 4 & 2 & 13.8 & 0.9 & 3.6 & 52.9 & 37.4 & 22.4 & 20.7 & 8.3 \\
\hline 5 & 3 & 12.0 & 0.7 & 2.4 & 53.0 & 39.4 & 20.5 & 20.6 & 8.7 \\
\hline 6 & $4 \mathrm{~N}$ & 9.0 & 1.2 & 2.2 & 52.2 & 38.6 & 21.5 & 20.3 & 8.3 \\
\hline 7 & $4 \mathrm{E}$ & 6.7 & 0.8 & 4.3 & 49.2 & 38.6 & 23.0 & 19.9 & 8.6 \\
\hline 8 & $4 \mathrm{~W}$ & 7.8 & 1.7 & 1.4 & 54.5 & 38.5 & 18.3 & 19.0 & 8.7 \\
\hline
\end{tabular}

UpS: average upslope steepness; Cv.: curvature; FC: volumetric water content at field capacity.

Table 4. Average values of TSWC, MRD and SDRD (after the 25 field surveys, $\theta_{0 i T}$ ) in different water content zones and those of the topographic and soil parameters with the highest Pearson's coefficients of correlation.

\begin{tabular}{|c|c|c|c|c|c|c|c|c|c|c|c|}
\hline Water content zone & \multicolumn{2}{|c|}{ Topography } & \multicolumn{4}{|c|}{ Soil } & \multicolumn{3}{|c|}{ TSWC } & MRD & SDRD \\
\hline & $\mathrm{UpS}$ & Cv. [+] & Rock & Silt & $\mathrm{CaCO}_{3}$ & FC & $\mathrm{mp}$ & mean & $\mathrm{sd}$ & mean & mean \\
\hline & $\%$ & $1 / 100$ & $\%$ & $\%$ & $\%$ & $\%$ vol. & $\mathrm{n}$ & \multicolumn{2}{|c|}{$\%$ vol. } & ratio & ratio \\
\hline Wettest & 10.6 & 0.8 & 0.7 & 56.3 & 37.8 & 28.3 & 16 & 23.8 & 8.3 & 0.189 & 0.236 \\
\hline Driest & 11.7 & 2.4 & 9.6 & 45.1 & 40.2 & 20.4 & 16 & 16.8 & 8.4 & -0.203 & 0.176 \\
\hline Stable \& M & 8.3 & 0.3 & 1.3 & 54.3 & 36.2 & 26.9 & 4 & 21.8 & 8.3 & 0.072 & 0.103 \\
\hline Stable \& D & 9.3 & 0.6 & 3.2 & 50.7 & 37.7 & 23.3 & 12 & 19.3 & 8.3 & -0.065 & 0.120 \\
\hline Medium stability \& M & 9.7 & 0.7 & 1.8 & 54.4 & 38.2 & 25.7 & 21 & 21.6 & 8.3 & 0.068 & 0.179 \\
\hline Medium stability \& D & 12.0 & 0.6 & 2.3 & 53.3 & 37.9 & 19.4 & 11 & 19.5 & 8.7 & -0.057 & 0.177 \\
\hline Most variable \& M & 14.7 & 2.1 & 3.1 & 51.8 & 37.3 & 25.3 & 12 & 22.6 & 8.5 & 0.125 & 0.321 \\
\hline Most variable \& D & 15.9 & ND & 2.4 & 50.7 & 38.8 & 24.8 & 4 & 18.9 & 8.8 & -0.075 & 0.279 \\
\hline
\end{tabular}

M: moist; D: dry; UpS: average upslope steepness; Cv.: curvature; FC: volumetric water content at field capacity; mp: measurement point; ND: no data. 